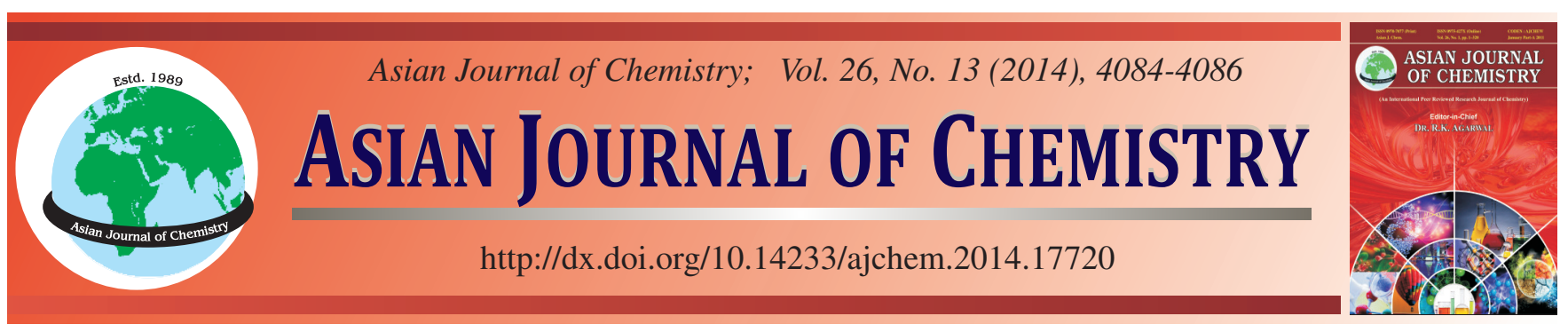

\title{
Determination of Triiodide Ion Concentration Using UV-Visible Spectrophotometry $\dagger$
}

\author{
SAnG-Hyuk Jung ${ }^{1,2}$, Jei-Won Yeon ${ }^{1, *}$, Yong KanG ${ }^{2, *}$ and KyuseoK Song ${ }^{1}$
}

${ }^{1}$ Nuclear Chemistry Research Division, Korea Atomic Energy Research Institute, Daedeokdaero 989-111, Yuseong-gu, Daejeon 305-353, Republic of Korea

${ }^{2}$ School of Chemical Engineering, Chungnam National University, Daehakro 99, Yuseong-gu, Daejeon 305-764, Republic of Korea

*Corresponding authors: E-mail: yeonysy@kaeri.re.kr; kangyong@cnu.ac.kr

Published online: 23 June 2014;

AJC-15415

The concentration of triiodide ions was determined using UV-visible spectrophotometry. The maximum absorption $\lambda_{\max }$ for the analysis of triiodide ions were observed at 288 and $351 \mathrm{~nm}$, with molar absorptivity values of $2.65 \times 10^{4}$ and $1.72 \times 10^{4} \mathrm{~L} \mathrm{~cm}^{-1} \mathrm{~mol}^{-1}$, respectively. The absorbance of triiodide ions had little effects on the solution $\mathrm{pH}$ in the range of 2.0 to 6.5 . However, the absorbance strongly depended on the iodide ion concentration. Consequently, we confirmed that triiodide ion concentrations in the range of $0.005-0.1 \mathrm{mM}$ could be determined using UV-visible spectrophotometry.

Keywords: Triiodide ion, UV-visible spectrophotometry, Iodide ion, Solution pH.

\section{INTRODUCTION}

The concentration of iodine species can be measured using several different analysis methods ${ }^{1-3}$. One of the most wellknown methods involves iodine titration with a thiosulfate solution $^{4,5}$. Total iodine can be analyzed using spectrometry, such as inductively coupled plasma-atomic emission spectrometry (ICP-AES), atomic absorption spectrometry (AAS) and inductively coupled plasma-mass spectrometry $(\mathrm{ICP}-\mathrm{MS})^{3,6,7}$. As elemental iodine has various valance states, various stable iodine species are present in aqueous solutions. Stable iodine species can include iodide ions, triiodide ions, iodine and iodate ions. For the quantitative analysis of these species, ion chromatography (IC) has been used in analytical laboratories ${ }^{3}$. In addition, ultraviolet-visible spectrophotometry and Raman spectrometry have been used for the speciation and quantitative analyses of iodine species $^{8,9}$.

Recently, after the severe accident at the Fukushima nuclear power plant in Japan, the chemical behaviour of radioactive iodine received increased attention as a result of interest in evaluating the volatility of iodine species, which depends on the chemical conditions of the exposed environments. The use of $\gamma$-ray spectroscopy to measure radioactivity is the best method for determining radioactive iodine concentrations. However, to use radioactive iodine, a licensed laboratory equipped with numerous radioactivity safety devices is generally required. Therefore, many researchers have performed their experiments using non-radioactive iodine under $\gamma$-ray radiation instead of radioactive iodine ${ }^{10}$. In this case, the analysis of iodine species should be performed by chemical methods. Similar to radioactive iodide ions, which are stably soluble in aqueous solution, non-radioactive iodide ions can also be oxidized into volatile iodine under $\gamma$-ray radiation.Under the selected experimental conditions, the iodide ion concentration is relatively high, allowing the oxidized species, molecular iodine,to react with iodide ions and form triiodide ions, which are the more stable soluble species. Therefore, it is important to measure the concentration of triiodide ions to evaluate the volatility of iodine species.

In the present work, we established a simple method to analyze the triiodide ion concentration using UV-visible spectrophotometry. First, we identified distinct absorption wavelengths and determined the maximum absorbance for the analysis of triiodide ions. Second, the absorbance of triiodide ions was confirmed to be independent of the solution $\mathrm{pH}$. Third, we evaluated the effect of iodide ions on the formation of triiodide ions by analyzing the UV-visible absorption spectra. Lastly, the detection range of triiodide ions was determined for the UV-visible spectrophotometric method. 


\section{EXPERIMENTAL}

An iodide solution (100 mM NaI) was obtained by the dissolution of sodium iodide and an iodine $\left(\mathrm{I}_{2}\right)$ solution was obtained by the dissolution of solid iodine in distilled water. A triiodide solution was prepared by adding the iodine solution to the sodium iodide solution and mixing. Thus, the triiodide ion concentration was mainly determined by the concentration of iodine $\left(\mathrm{I}_{2}\right)$ in the solutions. Iodide ions were added in excess to stable form the triiodide ion in the solutions. A perchloric acid solution $\left(0.1 \mathrm{M} \mathrm{HClO}_{4}\right)$ was used to control the solution $\mathrm{pH}$. All chemicals used were of analytical grade and all experiments were carried out at ambient temperature. A WPA Lightwave II UV-visible spectrophotometer was used (Biochrom Ltd).

\section{RESULTS AND DISCUSSION}

UV-visible absorption spectrum of triiodide ion: Fig. 1a shows the UV-visible absorption spectra of 0-0.15 mM triiodide ions. The solution $\mathrm{pH}$ was maintained at 6.5. The large absorption partially observed between 200 and $250 \mathrm{~nm}$ is attributed to the addition of iodide ions to the solutions in excess. The triiodide ions exhibited strong light absorption $\left(\varepsilon>10^{4} \mathrm{~L} \mathrm{~cm}^{-1}\right.$ $\left.\mathrm{mol}^{-1}\right)$ at 288 and $351 \mathrm{~nm}$. The maximum absorbance values at these two wavelengths increased with the triiodide ion concentration. The molar absorptivity values at 288 and 351 nm were $2.65 \times 10^{4}$ and $1.72 \times 10^{4} \mathrm{~L} \mathrm{~cm}^{-1} \mathrm{~mol}^{-1}$, respectively.
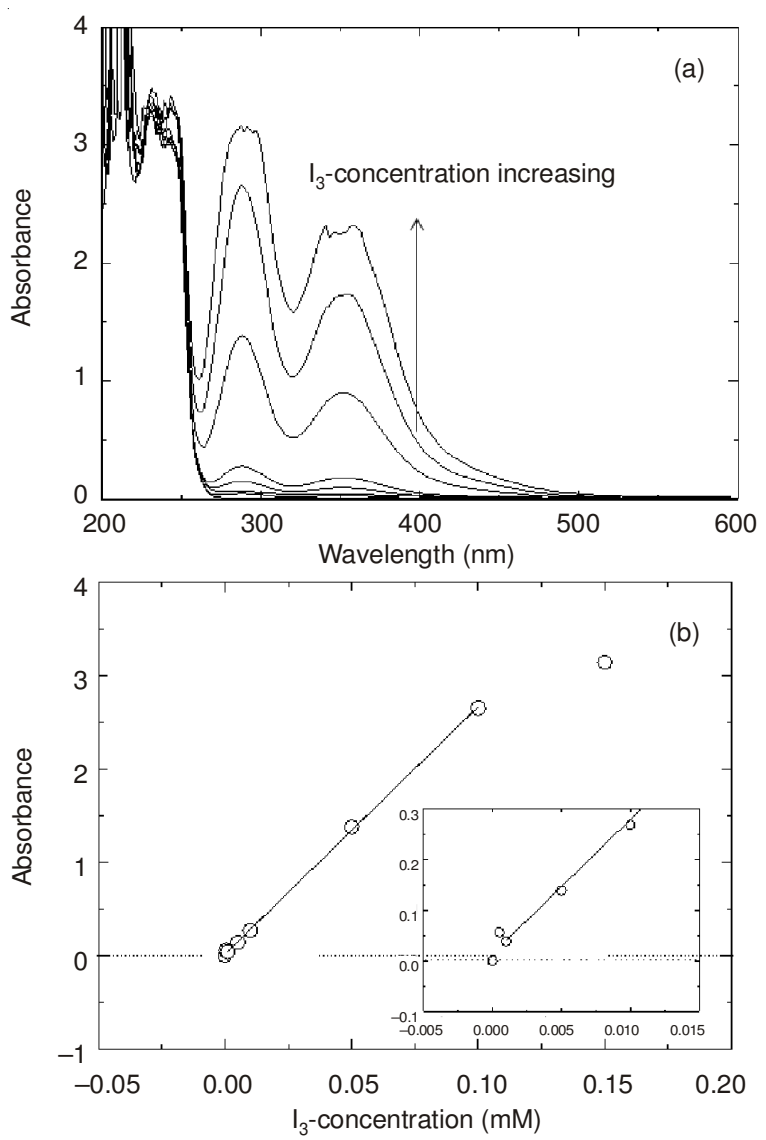

Fig. 1. (a) UV-visible absorption spectra of 0-0.15 mM triiodide ions. The solution $\mathrm{pH}$ was maintained at 6.5. (b) Relationship between the maximum absorbance value at $288 \mathrm{~nm}$ and triiodide ion concentration
Using the absorbance values presented in Fig. 1a, we obtained the relationship between the maximum absorbance value at $288 \mathrm{~nm}$ and triiodide ion concentration, as shown in Fig. 1b. A linear relationship was observed in the concentration range of $0.005-0.10 \mathrm{mM} \mathrm{I}_{3}{ }^{-}$, corresponding to the range of triiodide ion concentrations that could be determined using UV-visible spectrophotometry.

Effect of solution pH on the UV-visible absorption spectrum of triiodide ions: Fig. 2 shows the UV-visible absorption spectra of $0.1 \mathrm{mM}$ triiodide ion solutions at three different $\mathrm{pH}$ values: $2.0,4.0$ and 6.5 . Above a $\mathrm{pH}$ of 6.5 , it is well-known that the triiodide ion isdisproportionated into iodide and iodate ions according to reactions $(1,2)$. Therefore, in our experiments, we limited the solution $\mathrm{pH}$ below 6.5 .

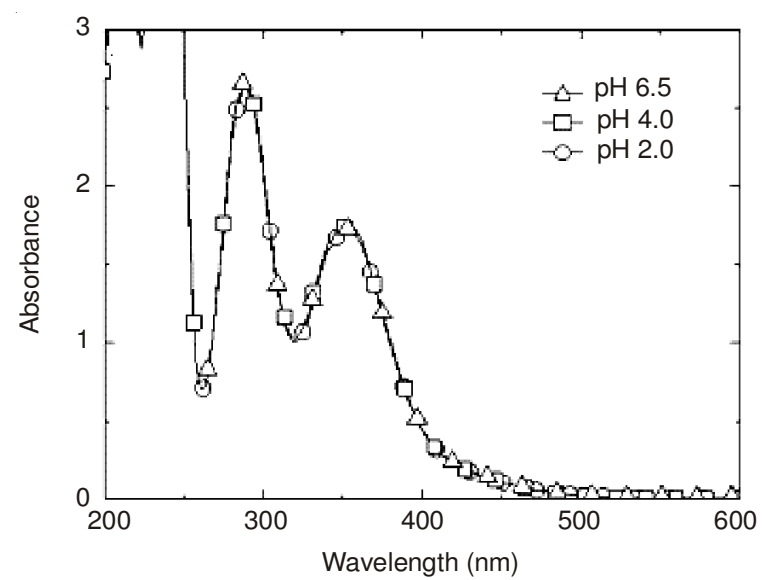

Fig. 2. UV-visible absorption spectra of $0.1 \mathrm{mM}$ triiodide ions. The solution $\mathrm{pH}$ was maintained at 2.0, 4.0 and 6.5

$$
\begin{gathered}
\mathrm{I}_{3}^{-}+2 \mathrm{OH}^{-} \longrightarrow 2 \mathrm{I}^{-}+\mathrm{IO}^{-}+\mathrm{H}_{2} \mathrm{O} \\
3 \mathrm{IO}^{-} \longrightarrow 2 \mathrm{I}^{-}+\mathrm{IO}_{3}^{-}
\end{gathered}
$$

As shown in Fig. 2, there was little change in the UV-visible absorption spectra at different solution $\mathrm{pH}$ values. This result confirmed that within this range, the solution $\mathrm{pH}$ has little effect on the determination of the triiodide ion concentration.

Interference of iodide ions in the UV-visible absorption spectrum of triiodide ions: Molecular iodine is stably soluble in its triiodide ion form in iodide solution, as shown in reaction (3). Although the equilibrium constant of the reaction is high, the concentration of triiodide ions dissolved in the iodide solution may depend on the concentration of iodide ions.

$$
\mathrm{I}_{2}+\mathrm{I}^{-} \rightleftharpoons \mathrm{I}_{3}^{-}
$$

We obtained triiodide solutions by adding iodine $\left(\mathrm{I}_{2}\right)$ to the sodium iodide solutions in four different concentrations and mixing. As the substantial concentration of iodine is 0.01 $\mathrm{mM}$, the concentration value of triiodide ion is approaching to $0.01 \mathrm{mM}$ with an increase in the iodide ion concentration. Fig 3a shows UV-visible absorption spectra of $0.01 \mathrm{mM}$ iodine $\left(\mathrm{I}_{2}\right)$ solution dissolved in sodium iodide solution. Two maximum absorptions without any spectral shift were also observed at 288 and $351 \mathrm{~nm}$. The absorbance values at these two wavelengths increased with an increase in the concentration of iodide ion up to $100 \mathrm{mM} \mathrm{I}^{-}$. This result indicates that the concentration of triiodide stabilized in the solutions depends sensitively on the concentration of iodide ion. 

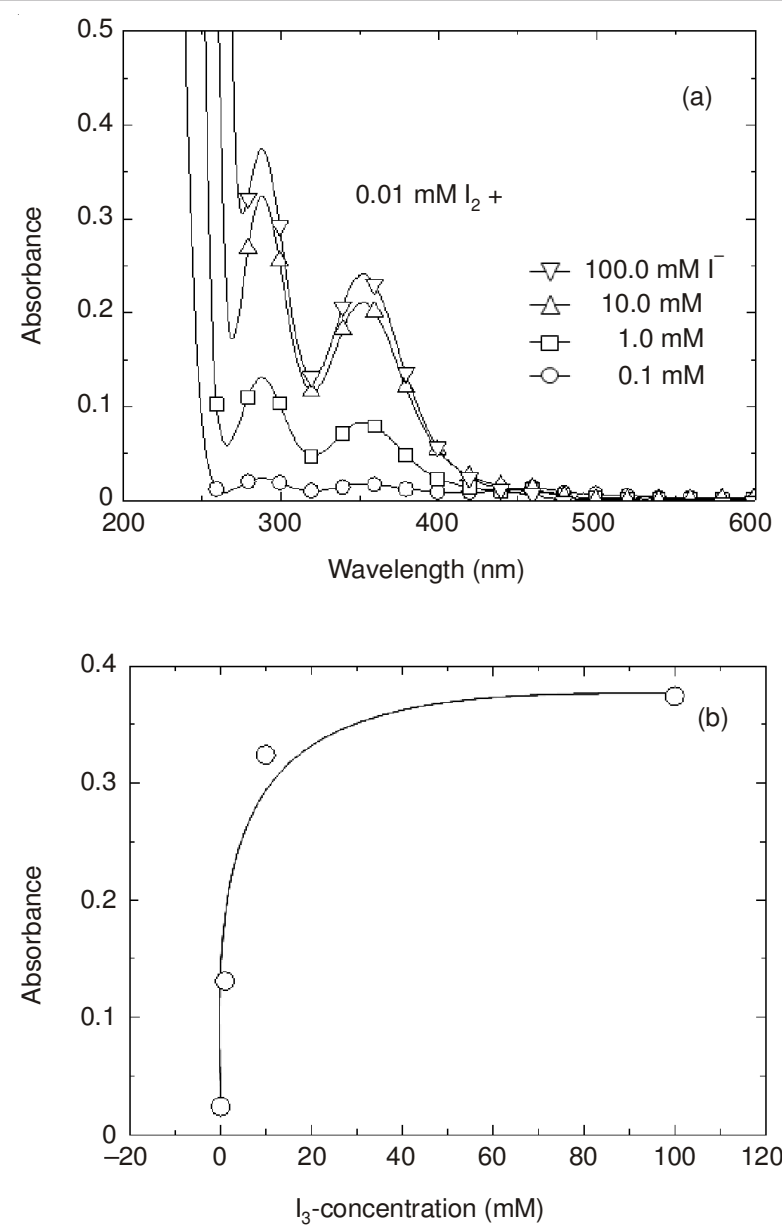

Fig. 3. (a) UV-visible absorption spectra of $0.01 \mathrm{mM}$ iodine $\left(\mathrm{I}_{2}\right)$ solution dissolved in iodide solutions offour different concentrations. (b) Relationship between the maximum absorbance of triiodide ion at $288 \mathrm{~nm}$ and the concentration of iodide ions

In Fig. 3b, the maximum absorbance $\lambda_{\max }$ of triiodide ion at $288 \mathrm{~nm}$ was plotted against the concentration of iodide ion. As the concentration of iodide ion increased, the absorbance value increased with approaching a maximum value. Thus, the absorbance value increased rapidly when the initial concentration of iodide ion was below $10 \mathrm{mM}$. However, above the concentration $10 \mathrm{mM}$, the absorbance value increased slowly and approached a certain value. The result indicates that the concentration of iodide ion in triiodide samples should be constant or relatively high, when the UV-visible spectroscopic analysis is used for a triiodide concentration determination method.

Triiodide ion determination range using UV-visible spectrophotometry: Considering the equilibrium between triiodide and iodide ions, we recorded UV-visible absorption spectra of various concentrations of triiodide ions with a constant iodide concentration of $5 \mathrm{mM}$. Fig 4 shows the relationship between the maximum absorbance $\lambda_{\max }$ at $288 \mathrm{~nm}$ and the initial concentration of molecular iodine added to the iodide solution. It was observed that the absorbance of triiodide ion increased linearly with the initial concentration of iodine without any interference of solution $\mathrm{pH}$. The result indicates that iodine concentrations of up to $0.1 \mathrm{mM}$ are completely converted into triiodide ions in a $5 \mathrm{mM}$ iodide solution. Based

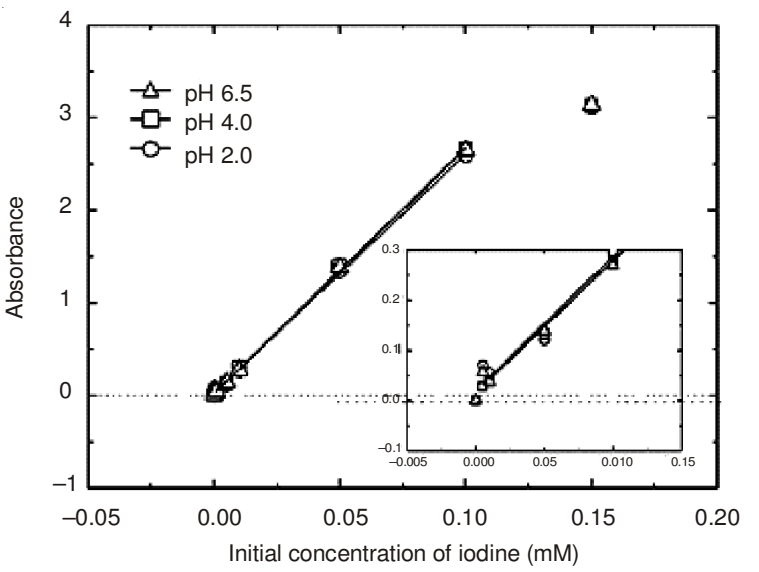

Fig. 4. Relationship between the maximum absorbance of triiodide ions at $288 \mathrm{~nm}$ and the initial concentration of molecular iodine added to the iodide solution

on the analysis of the inset in Fig. 4, we also found that the detection limit of triiodide ions was $0.005 \mathrm{mM}$. Therefore, it was concluded that triiodide ion concentrations of 0.005 to $0.1 \mathrm{mM}$ could be determined using UV-visible spectrophotometry as long as the solution $\mathrm{pH}$ was 2.0-6.5.

\section{Conclusion}

The triiodide ion was observed to have two distinct absorptions at 288 and $351 \mathrm{~nm}$ with molar absorptivity values of $2.65 \times 10^{4}$ and $1.72 \times 10^{4} \mathrm{~L} \mathrm{~cm}^{-1} \mathrm{~mol}^{-1}$, respectively. The absorbance of triiodide ions was independent of the solution $\mathrm{pH}$ from 2.0-6.5. However, the absorbance was strongly affected by the iodide ion up to $5.0 \mathrm{mM}$. Consequently, it was confirmed that triiodide ion concentrationsof $0.005-0.1 \mathrm{mM}$ could be determined using UV-visible spectrophotometry.

\section{ACKNOWLEDGEMENTS}

This work was supported by the Nuclear Research and Development Program through the National Research Foundation of Korea Funded by the Ministry of Science, Information Communication Technology and Future Planning, Republic of Korea.

\section{REFERENCES}

1. T.R. Crompton, Determination of Anion in Natural and Treated Waters, Taylor \& Francis e-Library, pp. 176-183 (2005).

2. V.R. Preedy, G.N. Burrow and R.R. Waston, Comprehensive Handbook of Iodine: Nutritional, Biochemical, Pathological and Therapeutic Aspects. Elsevier Inc., pp. 18-25 (2009).

3. A. Moreda-Piñeiro, V. Romarís-Hortas and P. Bermejo-Barrera, J. Anal. At. Spectrom., 26, 2107 (2011).

4. R.S. Burlage, R. Atlas, D. Stahl, G. Gessey and G. Sayler, Techniques in Microbial Ecology, Oxford University Press Inc., p. 48 (1998).

5. K. Grasshoff, K. Kremling and M. Ehrhardt, Methods of Seawater Analysis, Wiley-VCH, edn. 3, pp. 77-79 (1999).

6. T. Nakahara and T. Mori, J. Anal. At. Spectrom., 9, 159 (1994).

7. S. Yoshida, Y. Muramatsu, S. Katou and H. Sekimoto, J. Radioanal. Nucl. Chem., 273, 211 (2007).

8. O. Thomas and C. Burgess, UV-Visible Spectrophotometry of Water and Wastewater, Elsevier B.V., p. 348 (2007).

9. J.R. Durig, O.D. Bonner and W.H. Breazeale, J. Phys. Chem., 69, 3886 (1965).

10. C.-C. Lin, J. Inorg. Nucl. Chem., 42, 1101 (1980). 